\title{
CASE REPORT OF ACQUIRED PYROGLUTAMIC ACIDEMIA IN A PEDIATRIC PATIENT
}

\author{
Adrianne Rahde Bischoff', Alícia Dorneles Dornelles ${ }^{1}$, \\ Ana Luiza Tainski de Azevedo', \\ Valentina Coutinho Baldoto Gava Chakr²
}

\begin{abstract}
Pyroglutamic acid (also known as 5-oxoproline) is an organic acid intermediate of the gamma-glutamyl cycle. Accumulation of pyroglutamic acid is a rare cause of high anion gap metabolic acidosis. In the pediatric population, the congenital form of pyroglutamic acidemia has been extensively described. However, there are scarce reports of the acquired form of this condition in children. The urine test for organic acids confirms the diagnosis of pyroglutamic acidemia. We report the case of a 16-month-old girl who developed transient 5-oxoprolinemia associated with malnutrition and the use of acetaminophen and ampicillin for the treatment of acute otitis media and abdominal pain. The patient received 21-hour course of n-acetylcysteine with improvement of metabolic acidosis. This report highligts the need of considering pyroglutamic acidemia in the differencial diagnosis for high anion gap metabolic acidosis in pediatric patients with malnutrition and other risk factors.
\end{abstract}

Keywords: Glutathione synthetase deficiency; 5-oxoprolinemia; pyroglutamic acidemia; metabolic acidosis

Pyroglutamic acid (PGA) or 5-oxoproline is an organic acid intermediate of the gamma-glutamyl cycle. PGA accumulation is a rare cause of metabolic acidemia $^{1-3}$. In adults, the presence of certain underlying medical conditions and use of several drugs have been implicated in the development of transient pyroglutamic acidemia ${ }^{1-3}$. In the pediatric population, the congenital form of pyroglutamic acidemia has been described, ${ }^{4}$ as well as some scarce reports of acquired acidemia ${ }^{5,6}$. Urine tests for organic acids confirm the diagnosis of this condition ${ }^{3}$. We present a pediatric case of a patient who developed transient 5-oxoprolinemia following malnutrition and use of acetaminophen and ampicillin. We also briefly discuss the biochemistry related to PGA accumulation and risk factors linked to this pathologic process.

\section{CASE REPORT}

A previously healthy African-American 16-month-old girl was admitted to hospital because of non-intentional esophageal injury by caustic soda. She was the only child of nonconsanguineous parents, without known genetic diseases in the family. Upper gastrointestinal tract endoscopy revealed constriction $10 \mathrm{~cm}$ beyond superior dental arch, with enantema, friability, and exsudate bridges. Upper gastrointestinal X-ray series showed severe constriction of the middle and inferior esophagus. Stomach could not be properly evaluated due to aspiration of barium during exam; hence, it was considered as damaged. Therefore, the patient underwent jejunostomy for feeding. Afterwards, she was followed in an outpatient clinic and had significant weight loss (from $10 \mathrm{~kg}$, $\mathrm{z}$-score -0.19 , before the injury to $7.18 \mathrm{~kg}, \mathrm{z}$-score -3.49 , after three months) and was admitted for nutritional recovery. Maltodextrin was introduced to her
Clin Biomed Res. 2015;35(3):163-166

1 Serviço de Pediatria, Hospital de Clínicas de Porto Alegre. Porto Alegre, RS, Brasil.

2 Departamento de Pediatria, Universidade Federal do Rio Grande do Sul (UFRGS). Porto Alegre, RS, Brasil.

Corresponding author: Valentina C. B. G. Chakr E-mail: vchakr@hcpa.edu.br Departamento de Pediatria, Hospital de Clínicas de Porto Alegre

Rua Ramiro Barcelos, 2350, Largo Eduardo Zaccaro, Faraco. 90035-903, Porto Alegre, RS, Brasil. 
diet and the patient improved weight gain $(10 \mathrm{~g} / \mathrm{kg} /$ day $)$ and was discharged 15 days later (weight: $8.27 \mathrm{~kg}$ ).

On a follow-up outpatient visit, one week later, the patient presented again with significant weight loss $(6.99 \mathrm{~kg})$ and had to be readmitted. Upon arrival she was asymptomatic but had signs of mild dehydration. Laboratory tests showed hypoalbuminemia $(2.4 \mathrm{~g} / \mathrm{dL})$, normochromic-normocytic anemia ( $\mathrm{Hb} 10.2 \mathrm{~g} / \mathrm{dL})$, and high anion gap metabolic acidemia $(\mathrm{pH} 7.22$, $\mathrm{PCO}_{2}$ 23.3, $\mathrm{HCO}_{3}$ 9.4, BE -16, anion gap 17.6), as well as electrolyte disturbances (hyponatremia, hypomagnesemia and hypokalemia). Serum sodium was $132 \mathrm{mEq} / \mathrm{L}$ and serum chloride was $105 \mathrm{mEq} / \mathrm{L}$ at this time.

She was initially managed with fluid, magnesium, potassium and sodium bicarbonate replacement, with poor response regarding acidemia correction (pH 7.23, $\mathrm{PCO}_{2}$ 20.2, $\mathrm{HCO}_{3} 8.2, \mathrm{BE}-17.8$ ). Workup for high anion gap acidemia revealed elevated plasma lactate $(6.39 \mathrm{mmol} / \mathrm{L})$ and a urinary anion gap of -23 . At first, refeeding syndrome was suspected, but metabolic acidosis persisted for the next days (nadir $\mathrm{pH}$ and $\mathrm{HCO}_{3}=7.08$ and 4, respectively). Because the patient had severe malnutrition and duodenal bypass secondary to jejunostomy feeding, intravenous thiamine was started. However, treatment failed. Bacterial overgrowth was suspected due to abdominal distension and persistent diarrhea. The patient was treated with a 5-day course of metronidazol every 15 days. Empirical treatment with biotin, cobalamin and I-carnitine was also established without response. During hospital stay, the patient received amoxicillin and ampicilin (acute otitis media) and acetaminophen for several days due to fever (acute otitis media) and abdominal pain (abdominal distension due to bacterial overgrowth). Amoxicilin, ampicilin and acetaminophen were all given prior to the development of high anion gap acidemia. She developed periorbital, hands and feet edema. Echocardiogram was normal.

Since the patient had persistently poor weight gain despite adequate diet and signs of bacterial overgrowth, she was investigated for the presence of short bowel syndrome. It was hypothesized that she could have an improper position of the distal extremity of jejunal tube or a compromised small bowel absorptive surface secondary to acid injury. A radiography performed after injection of barium through the jejunostomy tube showed that its extremity was $4 \mathrm{~cm}$ far from the ileocecal valve, compatible with a jejuno-ileal fistula. Parenteral nutrition was then initiated and the patient started gaining weight $(8.9 \mathrm{~kg}-10 \mathrm{~g} / \mathrm{kg} /$ day) and improved her albumin levels $(4.1 \mathrm{~g} / \mathrm{dL})$.

Since severe metabolic acidemia persisted and lactate returned to normal levels, pyroglutamic acidemia was suspected. At this time, serum sodium was $133 \mathrm{mEq} / \mathrm{L}$ and serum chloride was $108 \mathrm{mEq} / \mathrm{L}$. PGA was moderately elevated in urine sample. The patient received a 21-hour course of n-acetylcysteine with improvement of metabolic acidemia ( $\mathrm{pH} 7.38, \mathrm{PCO}_{2} 39.1, \mathrm{HCO}_{3} 23$, EB -1.3, anion gap 7) (figure 1). PGA in the urine was within normal range after treatment. The patient had hyperglycemia during n-acetylcysteine infusion with dextrose $5 \%$. She was concomitantly receiving total parenteral nutrition with a $6.5 \mathrm{mg} / \mathrm{kg} / \mathrm{min}$ glucose infusion rate.

The patient progressed without new episodes of acidemia. All medications implicated in pyroglutamic acidemia were avoided. The patient underwent esophagectomy and gastric pull-up. Two thirds of esophagus were removed. During the procedure, the hypothesis of jejunal fistula was confirmed. At the reminiscent proximal esophagus, there was a severe stricture that was treated with dilations. The patient will be fed via nasoenteral tube until the dilations are completed and dysphagia is currently being treated by a speech therapist.

\section{DISCUSSION}

Transient severe anion gap metabolic acidosis due to 5-oxoprolinemia, also known as pyroglutamic acidemia, is a rare clinical condition caused by glutathione deficiency ${ }^{1-3}$. Although this condition is supposed to be encountered at any age, this is the third pediatric case reported ${ }^{5,6}$.

PGA is produced in the gamma-glutamyl cycle, responsible for generating glutathione and membrane transport of amino acids into cytosol. PGA is primarily metabolized to glutamate by enzyme 5-oxoprolinase and is eliminated by the renal system. In this pathway, normal glutathione stores are required for feedback suppression of the enzyme gamma-glutamyl cysteine synthetase, which controls the activity of the cycle $e^{1,7,8}$

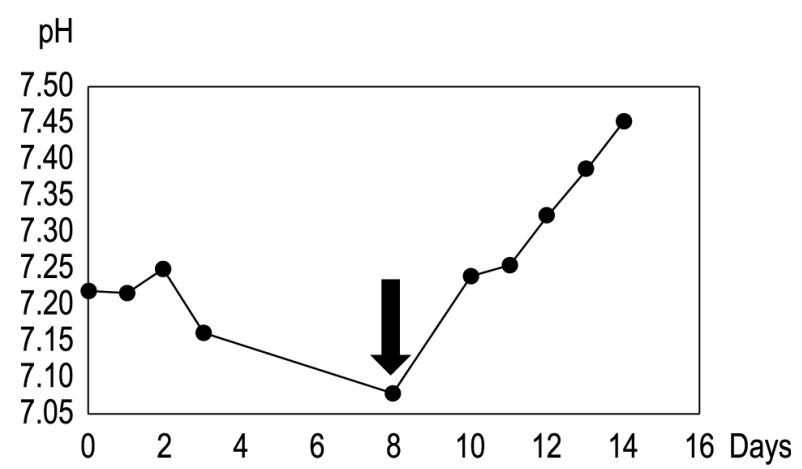

Figure 1: Effect of $\mathrm{n}$-acetylcysteine administration on $\mathrm{pH}$. Patient's $\mathrm{pH}$ increased after administration of intravenous n-acetylcysteine (arrow). 


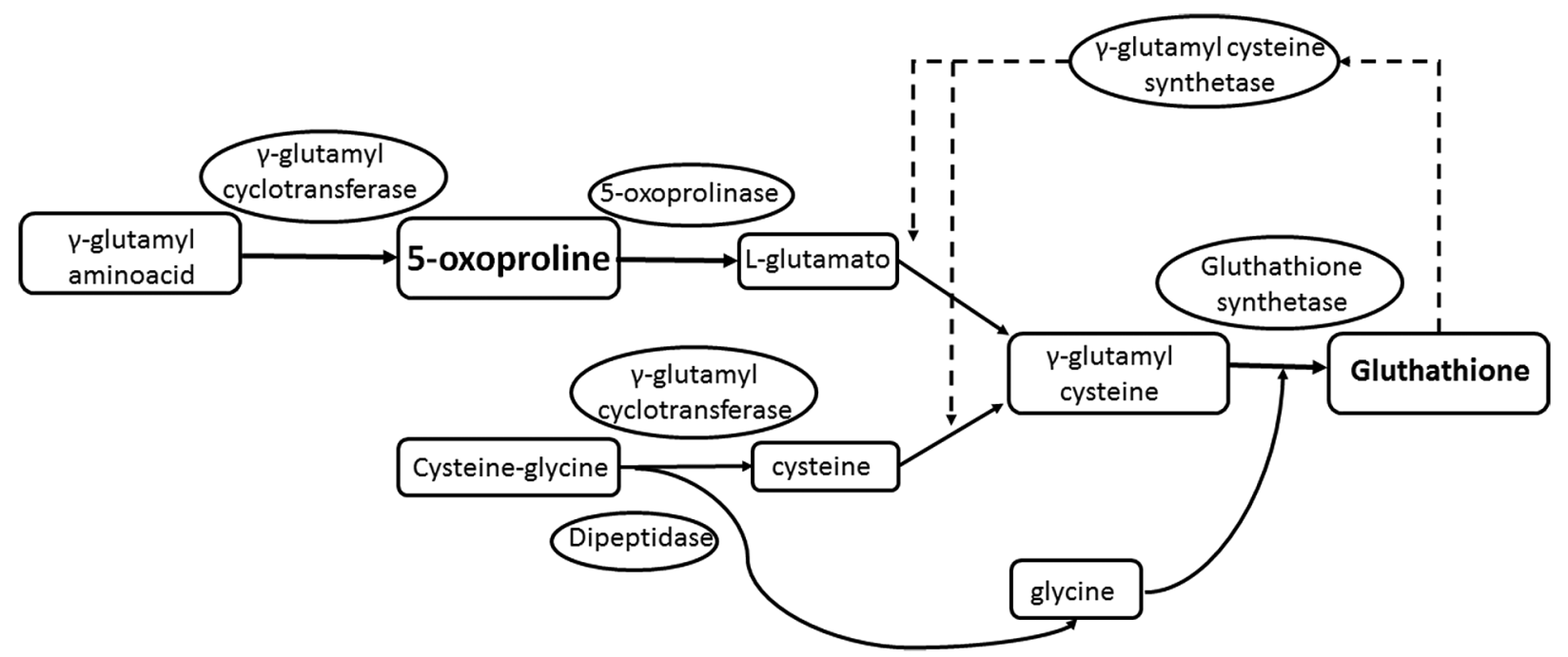

Figure 2: Gamma-glutamyl cycle.

(figure 2). High anion gap metabolic acidosis (HAGMA) caused by PGA results from lack of glutathione and disruption of the gamma-glutamyl cycle, once large amounts of gamma-glutamyl cysteine are metabolized by gamma-glutamyl cyclotransferase to produce PGA directly ${ }^{1,7}$.

It is well established in adults that the therapeutic use of acetaminophen combined with risk factors such as malnutrition, severe sepsis, artificial feeding, hepatic disease, diabetes, pregnancy, renal failure, and use of penicillin and vigabatrin is a cause of transient 5-oxoprolinemia ${ }^{1-3,8}$. Acetaminophen and vigabatrin deplete glutathione stores, leading to loss of feedback inhibition and increased production of 5-oxoproline from its precursor gamma-glutamyl cysteine. Without the aforementioned risk factors, acetaminophen alone is an unlikely cause of PGA-induced anion gap acidosis. Female gender is another likely risk factor ${ }^{2,8}$.

Our patient had risk factors that lead to PGA accumulation. She was severely malnourished and used acetaminophen and ampicillin for several days. The increased levels of lactic acid contributed to her acidemia, but the levels were not sufficient to explain the severity of acidosis. Metronidazole was also given prior to the development of acidemia, which may have contributed to the development of the disease. However, we were not able to find any article describing an association between the use of metronidazole and pyroglutamic acidemia. Therefore, we believe that ampicillin/amoxicillin and acetaminophen were the drugs most likely involved in the pathogenesis of the disease.

Some polymorphisms for the glutathione synthetase enzyme have been described, especially in cases of HAGMA with 5-oxoprolinemia that occur later in life under particular metabolic stress, suggesting a previously unrecognized genetic defect. Aside from the polymorphism, there also exists acquired glutathione synthetase deficiency because the enzyme may not perform equally well across the person's life span' 1 .

Hereditary 5-oxoprolinemia is a result of autosomal recessive deficiencies caused by hereditary error in one of the enzymes involved in the gamma-glutamyl cycle, as glutathione synthetase and 5-oxoprolinase deficiency ${ }^{3,8}$. These rare metabolic disorders usually present in neonates with hemolytic anemia and neurological defects ${ }^{1,7}$. Therefore, it is very unlikely that the girl described in our case report presented the hereditary form of the disease.

Concerning treatment, $n$-acetylcysteine use is a plausible option based on the glutathione deficiency of the disorder, as it provides the cysteine necessary for glutathione syntesis ${ }^{1}$. There are no strong evidence supporting its use, but it was shown to be effective in several cases reports ${ }^{9-12}$.

Previous reports of aquired pyroglutamic acidemia in pediatric patients also found that this condition was associated with the use of acetaminophen ${ }^{5,6}$. Arboledas et al. described a 16 month-old patient with hemolytic uremic syndrome that developed HAGMA requiring hemodialysis ${ }^{5}$, while Pitt et al. described one case associated with pneumonia in a 5 year-old child and one case of septic shock in a 1 year-old ${ }^{6}$. Only the latter patient was treated with $n$-acetylcysteine ${ }^{6}$. Our patient had malnutrition as a main risk factor for the development of the disease. No other case reports in children described malnutrition associated with acquired pyroglutamic acidemia. 


\section{CONCLUSION}

This report highlights the importance of considering PGA accumulation in the context of profound high anion gap metabolic acidemia in pediatrics patients with known risk factors for this condition, such as malnutrition, which can be easily and promptly corrected with appropriate treatment.

PGA: pyroglutamic acid

HAGMA: high anion gap metabolic acidosis

\section{Acknowledgements}

The authors thank the Medical Genetics Service of Hospital de Clínicas de Porto Alegre for their support and assistance with the diagnosis.

\section{Conflict of interest}

The authors declare no conflicts of interest.

\section{Funding}

No funding was secured for this study.

\section{REFERENCES}

1. Abkur TM, Mohammed W, Ali M, Casserly L. Acetaminopheninduced anion gap metabolic acidosis secondary to 5-oxoproline: a case report. $J$ Med Case Rep. 2014;8(1):409. http://dx.doi. org/10.1186/1752-1947-8-409. PMid:25479831.

2. Croal BL, Glen AC, Kelly CJ, Logan RW. Transient 5-oxoprolinuria (pyroglutamic aciduria) with systemic acidosis in an adult receiving antibiotic therapy. Clin Chem. 1998;44(2):33640. PMid:9474033.

3. Liss DB, Paden MS, Schwarz ES, Mullins ME. What is the clinical significance of 5-oxoproline (pyroglutamic acid) in high anion gap metabolic acidosis following paracetamol (acetaminophen) exposure? Clin Toxicol (Phila). 2013;51(9):817-27. http://dx.doi.or g/10.3109/15563650.2013.844822. PMid:24111553.

4. Larsson A, Mattsson B, Wauters EA, van Gool JD, Duran M, Wadman SK. 5-oxoprolinuria due to hereditary 5-oxoprolinase deficiency in two brothers: a new inborn error of the gamma-glutamyl cycle. Acta Paediatr Scand. 1981;70(3):301-8. http:// dx.doi.org/10.1111/j.1651-2227.1981. tb16556.x. PMid:6113726.

5. Arboledas FJA, Senovilla PO, Muñoz MJG, Melgar AA, Tarrío FR. Acidosis piroglutámica asociada a paracetamol. An Pediatr (Barc). 2007;67(6):582-4. http://dx.doi.org/10.1016/S16954033(07)70808-1. PMid:18053525.

6. Pitt JJ, Hauser S. Transient 5-oxoprolinuria and high anion gap metabolic acidosis: clinical and biochemical findings in eleven subjects. Clin Chem. 1998;44(7):1497503. PMid:9665429.

7. Chestnutt J, Heyburn G, Roberts B. Pyroglutamic aciduria: a cause of high anion-gap metabolic acidosis associated with common drugs. Ir Med J. 2011;104(10):312-3. PMid:22256446.

8. Kortmann W, van Agtmael MA, van Diessen J, Kanen BL, Jakobs C, Nanayakkara PW. 5-Oxoproline as a cause of high anion gap metabolic acidosis: an uncommon cause with common risk factors. Neth J Med. 2008;66(8):354-7. PMid:18809985.
9. O'Brien LM, Hooper M, Flemmer M, Marik PE. Chronic acetaminophen ingestion resulting in severe anion gap metabolic acidosis secondary to 5-oxoproline accumulation: an under diagnosed phenomenon. BMJ Case Rep. 2012;2012 PMid:22761219.

10. Rolleman EJ, Hoorn EJ, Didden $P$, Zietse R. Guilty as charged: unmeasured urinary anions in a case of pyroglutamic acidosis. Neth $\mathrm{J}$ Med. 2008;66(8):351-3. PMid:18809984.

11. Brooker G, Jeffery J, Nataraj T, Sair M, Ayling R. High anion gap metabolic acidosis secondary to pyroglutamic aciduria (5-oxoprolinuria): association with prescription drugs and malnutrition. Ann Clin Biochem. 2007;44(Pt 4):406-9. http://dx.doi. org/10.1258/000456307780945769. PMid:17594793.

12. Hodgman MJ, Horn JF, Stork CM, Marraffa JM, Holland MG, Cantor $\mathrm{R}$, et al. Profound metabolic acidosis and oxoprolinuria in an adult. $\mathrm{J}$ Med Toxicol. 2007;3(3):119-24. http:// dx.doi.org/10.1007/BF03160921. PMid:18072147. 